\title{
Pathological profiles and clinical management challenges of breast cancer emerging in young women in Indonesia: a hospital-based study
}

Sumadi Lukman Anwar ${ }^{1,2^{*}}$ (D), Clarista Adelia Raharjo ${ }^{1}$, Rahma Herviastuti ${ }^{1}$, Ery Kus Dwianingsih ${ }^{3}$, Didik Setyoheriyanto ${ }^{3}$, Widya Surya Avanti ${ }^{4}$, Lina Choridah", Wirsma Arif Harahap ${ }^{5}$, Darwito ${ }^{1}$,

Teguh Aryandono ${ }^{1}$ and Wahyu Wulaningsih ${ }^{2,6}$

\begin{abstract}
Background: Breast cancer diagnosed at a young age is often associated with aggressive biology, advanced stage, and unfavorable prognosis. The median age of breast cancer diagnosis in Indonesia is younger (48 vs. 68 years-old in Europe) with a relatively higher proportion of patients younger than 40 years old. Although prognosis and outcome of young breast cancer are well studied in developed nations, research evaluating biological characteristics, delivered treatment, and clinical outcomes is very limited in Indonesia.

Methods: We analyzed all breast cancer patients who underwent surgery at Dr. Sardjito Hospital, Indonesia, in 20122017. Details of pathology profiles, treatment administrated, and outcomes, as well as reproductive factors among patients younger than 40 years old, were collected and analyzed. Kaplan-Meier curve was used to assess conditional survival based on baseline characteristics.
\end{abstract}

Results: From the total of 1259 breast cancer patients (median age 51 years), 144 (11.4\%) were younger than 40 years old (median age 37 years). Of these young patients, 19 (13.2\%) were bilateral and 92 (64\%) were diagnosed in advanced stages (stages IIIA-C and IV). Median tumor diameter was $5.5 \mathrm{~cm}$ and nodal infiltration was present in $73 \%$. Distant metastasis was found in $16 \%$ at the time of diagnosis. Moderate and poor differentiation of tumor were 20.8 and $78.5 \%$, respectively, and lymphovascular invasion was found in $90.3 \%$. Around $40 \%$ were hormone receptor-positive, 30.6\% human epidermal growth factor receptor 2 positive, and 38.2\% triple negative. Patients underwent radical surgery in 121 cases (84\%) and breast conserving surgery in 7 cases (4.9\%). Adjuvant chemotherapy was administrated in $68 \%$ and hormonal therapy in $34 \%$. Progression-free survival was significantly shorter in patients with advanced stage, skin and chest wall involvement (T4), positive lymph node infiltration, positive hormonal receptor, and triple negative subtype (log-rank Mantel-Cox tests, $p<0.05$ ).

Conclusion: We found a high frequency of young breast cancer with biologically more aggressive tumors, late diagnosis, frequent relapse, and poor prognosis. Further actions to improve clinical management and meet psychosocial needs in young breast cancer patients are warranted.

Keywords: Young breast cancer, Subtype, Progression free survival, Psychosocial need, Indonesia

\footnotetext{
* Correspondence: sl.anwar@ugm.ac.id

'Division of Surgical Oncology-Department of Surgery, Faculty of Medicine,

Public Health and Nursing, Universitas Gadjah Mada (Dr. Sardjito Hospital),

Jalan Kesehatan No 1, Yogyakarta 55281, Indonesia

${ }^{2}$ PILAR Research and Education, 20 Station Road, Cambridge CB1 2JD, UK

Full list of author information is available at the end of the article
}

(c) The Author(s). 2019 Open Access This article is distributed under the terms of the Creative Commons Attribution 4.0 International License (http://creativecommons.org/licenses/by/4.0/), which permits unrestricted use, distribution, and reproduction in any medium, provided you give appropriate credit to the original author(s) and the source, provide a link to the Creative Commons license, and indicate if changes were made. The Creative Commons Public Domain Dedication waiver (http://creativecommons.org/publicdomain/zero/1.0/) applies to the data made available in this article, unless otherwise stated. 


\section{Background}

Breast cancer has emerged as the most diagnosed cancer and the leading cause of cancer-related mortality among women worldwide [1]. More than 2 million females are diagnosed each year with annual mortality over 600,000 [1]. In Indonesia, the total incidence of breast cancer in 2014 was $\sim 50,000$ and annual mortality was $\sim 20,000$ [2]. In general, the incidence of breast cancer in young women is relatively low worldwide. Median age at diagnosis is 68 years in developed nations [3, 4], while in Indonesia median age at diagnosis is $\sim 48$ years-old including more than 5000 women under 40 years who are annually diagnosed with breast cancer [2].

Young age is associated with worse prognosis in breast cancer $[5,6]$ which may be partly explained by different biological mechanisms in young patients. Young breast cancers (YBCs) exhibit more aggressive characteristics [7] including higher rates of mitotic index, poor tumor differentiation, triple-negative subtype, with higher propensity for relapse and distant metastasis $[6,7]$. In low and middle-income countries (LMIC) including Indonesia, a delayed presentation may additionally play a role as there is a lack of population-based screening programs [8]. There is also low cancer awareness in Indonesian women, particularly those with lower household expenditure and education levels, which may contribute to a delayed diagnosis of breast cancer including among young women [8]. Specific considerations in comprehensive cancer care, surveillance plans, adherence to adjuvant therapy as well as management of side effects in YBC patients are required to achieve optimal therapeutic and long-term outcome results. However, little is known regarding the clinical characteristics associated with prognosis of young women with breast cancer in Indonesia, which could be used to better inform strategies to improve care for these patients.

To gain further understanding regarding young women with breast cancer in Indonesia, in this study we presented baseline clinicopathological factors and treatment choice and prognosis of YBC patients in a tertiary referral hospital-based case series in Indonesia. We also assessed the relationship between these factors and progression free survival (PFS) then discussed these findings in relation to other determining factors and made recommendations to improve clinical management of young patients with breast cancer in Indonesia.

\section{Methods}

\section{Design and population of the study}

All breast cancer patients who underwent surgery at the Department of Surgery, Sardjito Hospital in 2012-2017 were collected, which included a total of 1259 breast cancer patients. Of this population, $114(11.4 \%)$ were 40 years old or younger, thereby meeting the definition of
YBC and were included in the analysis of young patients with breast cancer. The study was approved by the Ethical Committee Faculty of Medicine Universitas Gadjah Mada Yogyakarta (1143/EC/2017) and informed consent was acquired from each participant.

\section{Data collection}

Data were drawn retrospectively from patients' medical records including age, clinical data, cancer stage, tumor size, lymph node infiltration, metastasis, histological grade, hormonal receptors, delivered treatments (surgery, chemotherapy, radiotherapy, and hormonal therapy) were collected and summarized.

YBC was defined as breast cancer patients aged 40 years or younger. Tumors were classified using the Tumor-Node-Metastasis (TNM) system according to the seventh edition of the ${ }^{1}$ American Joint Committee on Cancer (AJCC) classification of 2009 [9]. Tumor grade was evaluated using the Nottingham modification of the Bloom and Richardson system (mSBR) [10]. Histological type was determined according to the World Health Organization (WHO) classification of breast cancer 2012 [11]. Vascular, lymphatic, and neural invasion were histologically quantified. Estrogen and Progesterone receptors (ER and PR) were considered positive if the nuclear expression was higher than $1 \%$ of tumor cells. Expression of human epidermal growth factor receptor 2 (HER2) was determined by immunohistochemistry (IHC) staining of cytoplasmic membrane and scored accordingly for which $0 / 1+$ is negative and +3 is positive. For tumors with +2 of HER2 IHC-staining or ambiguous results, Fluorescence in Situ Hybridization (FISH) was performed and any evidence of HER2 amplification was considered as positive. Based on the ER, PR, and HER2 IHC-staining results, breast cancers were classified as Luminal A (ER+/PR+/HER2+), Luminal B (ER+/PR-/HER2+), HER2 (ER-/PR-/HER2+) or triple negative breast cancer (TNBC) (ER-/PR-/HER2-) [5].

Smoking status was assessed during interviews after diagnosis of breast cancer and was then categorized into active or former smoker if respondent actively or ever smoked more than 100 cigarettes in their lifetime. Physical activity was classified into vigorous if the activity was performed more than $2 \mathrm{~h}$ per week and resulted in rapid heartbeat and breathless (jogging, aerobic, rigorous swimming/cycling), moderate if the activity was performed more than $2 \mathrm{~h}$ per week and caused exhaustion but not breathless (easy swimming/cycling, dancing, yoga, pilates), and light activity if the activity caused tiredness but not exhaustion (walking, driving, housework). Although we did not directly measure the ratio of work to a standard resting metabolic rate (MET), the categorization of physical activity was estimated according to a specific type of 
activity [12]. The residence was classified into urban (kota) and rural (desa) based on official administrative status given by the Indonesian government to the place where a patient was living at the time of diagnosis (shown by their identity cards). Positive family history was defined if first- or second-degree relative had a history of breast and/or ovarian cancer. Parity was determined by the number of full-term pregnancies and categorized into null- or multi-parity.

\section{Follow-up}

Patients received follow-up from the date of diagnosis until any tumor progression was recorded, until they died or until the last date of the study in February 2018. Follow-up visits were scheduled every month for the first 6 months and every 6 months after completion of therapy unless any non-scheduled visit was indicated, and involved a thorough clinical examination, breast sonography and/or mammography, abdominal ultrasonography, chest X-ray, and bone scan. PFS was calculated starting from the time elapsed of diagnosis to tumor progression or death from any cause.

\section{Statistical analysis}

SPSS 17.0 software (IBM) was used for conducting the statistical analysis. Descriptive variables were presented in means \pm standard deviation (SD) or medians. The Mann-Whitney-U test was used to compare continuous variables and the $\chi^{2}$ test to compare categorical variables. Kaplan-Meier survival curve and log-rank Mantel-Cox tests compared PFS across different clinicopathological characteristics and treatment outcomes. Cox regression was used to identify factors influencing PFS. For all comparisons, $p<0.05$ was considered as statistically significant.

\section{Results}

Demographic and clinicopathological characteristics

Of the YBC patients, the median age at diagnosis was 37 years and $39.6 \%$ were younger than 35 years old (Table 1). The majority of patients were Javanese decent (and living in rural areas, 86.1\%), high school graduates or of lower educational level (79\%), married (97.2\%), non-smokers (96.5\%), and sedentary (72.9\%) (Table 1). Five patients $(3.5 \%)$ were diagnosed with breast cancer during pregnancies and 19 patients (13.2\%) were bilateral breast cancers.

Around $7 \%$ of patients reported having first- or second-degree relative with breast or ovarian cancer. The majority of patients had at least one full-term pregnancy $(88.2 \%)$. Breast lumps and skin induration or lesions were the most common reason to seek treatment (65.3 and 25.7\%, respectively). All patients reported themselves as right-handed and $47 \%$ of the tumors were
Table 1 Sociodemographic characteristics of young breast cancer patients $(N=144)$ and their associations with disease progression (HR hazard ratio, $\mathrm{Cl}$ confidence interval)

\begin{tabular}{|c|c|c|c|}
\hline Parameters & $\mathrm{N}$ & $\%$ & HR $(95 \% \mathrm{Cl})$ \\
\hline \multicolumn{4}{|l|}{ Age at diagnosis } \\
\hline Median & 37 & & \\
\hline$<35$ & 57 & $39.60 \%$ & $0.937(0.376-2.273)$ \\
\hline$\geq 35$ & 87 & $60.40 \%$ & ref \\
\hline \multicolumn{4}{|l|}{ Ethnicity } \\
\hline Javanese & 130 & $90.30 \%$ & $1.581(0.387-6.462)$ \\
\hline Banjar & 4 & $2.80 \%$ & ref \\
\hline Sundanese & 3 & $2.10 \%$ & ref \\
\hline Dayak & 3 & $2.10 \%$ & ref \\
\hline Chinese & 2 & $1.40 \%$ & ref \\
\hline Others & 2 & $1.40 \%$ & ref \\
\hline \multicolumn{4}{|l|}{ Residence } \\
\hline Rural & 124 & $86.10 \%$ & $1.021(0.365-2.861)$ \\
\hline Urban & 20 & $13.90 \%$ & ref \\
\hline \multicolumn{4}{|l|}{ Education } \\
\hline Less than high school & 34 & $23.60 \%$ & $0.836(0.334-2.092)$ \\
\hline High school & 80 & $55.60 \%$ & ref \\
\hline Higher education & 30 & $20.80 \%$ & ref \\
\hline \multicolumn{4}{|l|}{ Marital status } \\
\hline Married & 140 & $97.20 \%$ & 1.985 (0.2-19.689) \\
\hline Not married & 4 & $2.80 \%$ & ref \\
\hline \multicolumn{4}{|l|}{ Physical activity } \\
\hline Vigorously active & 17 & $11.80 \%$ & ref \\
\hline Moderately active & 22 & $15.30 \%$ & $0.230(0.086-0.615)$ \\
\hline Lightly active & 105 & $72.90 \%$ & ref \\
\hline \multicolumn{4}{|l|}{ Tobacco smoking } \\
\hline Never & 139 & $96.50 \%$ & 1.985 (0.2-19.689) \\
\hline Ever & 3 & $2.10 \%$ & ref \\
\hline Former & 2 & $1.40 \%$ & ref \\
\hline
\end{tabular}

located in the right breast. The median size of the tumor was $5.5 \mathrm{~cm}$ and the majority were larger than $3 \mathrm{~cm}$ (84\%). Lymph node infiltration was found in $73 \%$ of cases and distant metastasis at diagnosis was discovered in $16 \%$ of cases. In total, $36 \%$ of cases were early stage-, $47.9 \%$ were locally advanced-, and $16 \%$ were metastatic breast cancers. More than $80 \%$ of YBC cases were histologically infiltrative ductal carcinomas. Positivity of hormonal receptors and HER2 expression were reported in 39.6 and $30.6 \%$, respectively. Molecular classification using IHC-staining revealed $43 \%$ patients as luminaland $38 \%$ as TNBC (Table 2). Ki67 IHC staining was documented in 34 patients in which 19 patients $(55.8 \%)$ were above $14 \%$ indicating a high mitotic index. 
Table 2 Clinical and pathological variables in young breast cancer patients $(N=144)$ and their associations with disease progression (HR hazard ratio, $\mathrm{Cl}$ confidence interval)

\begin{tabular}{|c|c|c|c|}
\hline Variables & $\mathrm{N}$ & $\%$ & $\mathrm{HR}(95 \% \mathrm{Cl})$ \\
\hline \multicolumn{4}{|c|}{ The family history of breast cancer } \\
\hline No & 133 & $92.40 \%$ & $0.969(0.258-3.640)$ \\
\hline Yes & 11 & $7.60 \%$ & ref \\
\hline \multicolumn{4}{|l|}{ Parity } \\
\hline Nulliparity & 17 & $11.80 \%$ & $1.925(0.647-5.730)$ \\
\hline Multiparity & 127 & $88.20 \%$ & ref \\
\hline \multicolumn{4}{|l|}{ Chief presentation } \\
\hline Breast lump & 94 & $65.30 \%$ & $1.295(0.6-2.795)$ \\
\hline Skin induration or lesion & 37 & $25.70 \%$ & ref \\
\hline Axillary mass & 4 & $2.80 \%$ & \\
\hline Pain & 9 & $6.30 \%$ & \\
\hline \multicolumn{4}{|l|}{ Positive biopsy diagnosis } \\
\hline Fine needle aspiration & 82 & $56.90 \%$ & N/A \\
\hline Biopsy & 62 & $43.10 \%$ & N/A \\
\hline \multicolumn{4}{|l|}{ Localization } \\
\hline Right & 68 & $47.20 \%$ & $3.839(1.045-14.112)$ \\
\hline Left & 51 & $39.60 \%$ & \\
\hline Bilateral & 19 & $13.20 \%$ & ref \\
\hline \multicolumn{4}{|l|}{ Multifocal lumps } \\
\hline No & 118 & $82 \%$ & $3.839(1.045-14.112)$ \\
\hline Yes & 26 & $18 \%$ & ref \\
\hline \multicolumn{4}{|l|}{ Tumor size } \\
\hline Median & $5.5 \mathrm{~cm}$ & & \\
\hline$>3$ & 121 & $84 \%$ & $3.8(1.04-14.11)$ \\
\hline$\leq 3$ & 23 & $16 \%$ & ref \\
\hline \multicolumn{4}{|l|}{ Lymph node involvement } \\
\hline positive & 108 & $75 \%$ & $2.159(0.912-5.108)$ \\
\hline negative & 36 & $25.00 \%$ & ref \\
\hline \multicolumn{4}{|l|}{ Stage } \\
\hline 1 & 5 & $3.50 \%$ & ref \\
\hline$\|$ & 47 & $32.60 \%$ & \\
\hline III & 69 & $47.900 \%$ & $0.610(0.278-1.339)$ \\
\hline IV & 23 & $16 \%$ & \\
\hline \multicolumn{4}{|l|}{ Distant metastasis at diagnosis } \\
\hline Yes & 23 & $16 \%$ & 8.627 (1.909-38.994) \\
\hline No & 121 & $84 \%$ & ref \\
\hline \multicolumn{4}{|l|}{ Histology } \\
\hline Ductal & 117 & $81.30 \%$ & $1.568(0.289-8.501)$ \\
\hline Lobular & 12 & $8.30 \%$ & ref \\
\hline Ductolobuler & 8 & $5.60 \%$ & \\
\hline Others & 7 & $4.80 \%$ & \\
\hline
\end{tabular}

Table 2 Clinical and pathological variables in young breast cancer patients $(N=144)$ and their associations with disease progression (HR hazard ratio, $\mathrm{Cl}$ confidence interval) (Continued)

\begin{tabular}{|c|c|c|c|}
\hline Variables & $\mathrm{N}$ & $\%$ & $\mathrm{HR}(95 \% \mathrm{Cl})$ \\
\hline \multicolumn{4}{|l|}{ mSBR grading } \\
\hline । & 1 & $0.70 \%$ & $0.836(0.334-2.092)$ \\
\hline$\|$ & 30 & $20.80 \%$ & \\
\hline III & 113 & $78.50 \%$ & ref \\
\hline \multicolumn{4}{|l|}{ Angioinvasion } \\
\hline No & 6 & $4.20 \%$ & $0.761(0.134-4.335)$ \\
\hline Yes & 138 & $95.80 \%$ & ref \\
\hline \multicolumn{4}{|l|}{ Lymphatic invasion } \\
\hline No & 14 & $9.70 \%$ & $2.513(0.668-9.447)$ \\
\hline Yes & 130 & $90.30 \%$ & ref \\
\hline \multicolumn{4}{|l|}{ Hormonal receptor } \\
\hline Negative & 86 & $59.70 \%$ & $1.6(0.753-3.398)$ \\
\hline Positive & 57 & $39.60 \%$ & ref \\
\hline \multicolumn{4}{|l|}{ HER2 expression } \\
\hline Negative & 99 & $68.80 \%$ & $0.623(0.281-1.382)$ \\
\hline Positive & 44 & $30.60 \%$ & ref \\
\hline \multicolumn{4}{|c|}{ Molecular classification } \\
\hline Triple Negative & 55 & $38.20 \%$ & $2.209(0.945-5.162)$ \\
\hline Luminal & 62 & $43.10 \%$ & ref \\
\hline HER2 & 26 & $18.10 \%$ & \\
\hline
\end{tabular}

\section{Treatment choice}

Operable breast cancers (T1-T2 N0-N1 M0 and T3N0M0) were diagnosed in $36 \%(N=52)$ and $13.5 \%$ of the patients who received breast-conserving surgery (Table 2 and Table 3). Locally advanced breast cancers (N2N3M0, T4M0, and T3N1M0) represented nearly $50 \%$ of cases $(N=69)$ and $8.7 \%$ of those who received neoadjuvant chemotherapy. In total, radical and palliative surgery was performed in 84 and $11 \%$ of cases, respectively. Adjuvant chemotherapy was completed in $68 \%$ of cases meanwhile nearly $12 \%$ of patients did not receive chemotherapy. Of 57 patients with hormone receptor positive, $86 \%$ received hormonal therapy. Targeted therapy in HER2-positive tumors was delivered in $41 \%$ of cases (18 of 44 patients). In addition, bisphosphonate treatment was administrated in $74 \%$ of patients with bone metastasis. Around 18 and $20 \%$ of patients did not show up for chemotherapy and radiotherapy, respectively. Comparing patients who received and did not receive chemotherapy (118 vs. 26 patients) and radiotherapy (102 vs. 41 patients) with their education levels (less or higher than high school, 34 vs. 110 patients) and residence (rural-urban, 124 vs. 20 patients) resulted in no statistical difference. As a 
Table 3 Treatment modalities in young breast cancer patients $(N=144)$ and their associations with disease progression (HR hazard ratio, Cl confidence interval)

\begin{tabular}{|c|c|c|c|}
\hline Treatment modalities & $\mathrm{N}$ & $\%$ & $\mathrm{HR}(95 \% \mathrm{Cl})$ \\
\hline \multicolumn{4}{|l|}{ Surgery } \\
\hline Palliative & 16 & $11.10 \%$ & $2.915(0.775-10.965)$ \\
\hline Radical & 121 & $84 \%$ & ref \\
\hline Conservative & 7 & $4.90 \%$ & \\
\hline \multicolumn{4}{|l|}{ Chemotherapy } \\
\hline Neoadjuvant & 6 & $4.20 \%$ & $1.667(0.310-8.976)$ \\
\hline Adjuvant & 98 & $68 \%$ & \\
\hline Palliative & 23 & $16 \%$ & \\
\hline No & 26 & $11.80 \%$ & ref \\
\hline \multicolumn{4}{|l|}{ Radiotherapy } \\
\hline No & 29 & $20.10 \%$ & $0.836(0.321-2.1770$ \\
\hline Waiting list & 13 & $9 \%$ & \\
\hline Yes & 102 & $70.80 \%$ & ref \\
\hline \multicolumn{4}{|l|}{ Hormonal therapy } \\
\hline Yes & 49 & $34 \%$ & ref \\
\hline No & 8 & $5.60 \%$ & $1.04(0.49-2.207)$ \\
\hline HR-negative & 86 & $59.700 \%$ & \\
\hline \multicolumn{4}{|l|}{ Anti-HER2 therapy } \\
\hline HER2 positive & 44 & $30.60 \%$ & \\
\hline No & 26 & $18.10 \%$ & $0.844(0.203-3.504)$ \\
\hline Yes & 18 & $12.50 \%$ & ref \\
\hline \multicolumn{4}{|c|}{ Bisphosphonate treatment } \\
\hline Yes & 17 & $11.80 \%$ & N/A \\
\hline No & 6 & $4.20 \%$ & N/A \\
\hline Bone metastases & 23 & $16 \%$ & \\
\hline
\end{tabular}

result, barriers to seeking chemotherapy and radiotherapy were not associated with residence and education levels (Fisher exact test, $p>0.05$ ).

\section{Progression-free survival (PFS) data}

Twenty-nine patients were lost during follow-up, so PFS data were only available for $115(80 \%)$ patients. Therefore, interpretations related to PFS need to be considered according to the context with potential surveillance or selection bias on the reported prevalence of relatively longer survival of YBC patients. During follow-up, 35 (24.3\%) patients developed distant metastasis and 10 (6.9\%) suffered from locoregional recurrence after a mean duration of 20.3 months. Survival probabilities based on clinicopathological factors are shown using the Kaplan-Meier curve in Fig. 1. Based on log-rank Mantle-Cox tests, PFS was significantly higher in early stages (stages I-II) compared to more advanced stages (median survival 42 vs. 29 months respectively, $p=$ $0.037 ; \mathrm{HR}=0.58,95 \% \mathrm{CI}: 0.34-0.98)$. Shorter PFS was found in patients with skin and chest wall infiltration (T4) compared to those without skin/chest wall infiltration (T1-T3) (median survival 16 vs. 35 months, $p=$ $0.011 ; \mathrm{HR}=1.89,95 \% \mathrm{CI}: 1.12-3.21$ ), positive lymph node infiltration (median survival 24 vs. 42 months, $p=$ $0.041 ; \quad H R=1.95, \quad 95 \% \mathrm{CI}: \quad 1.05-3.64), \quad$ hormonal receptor-positive compared to negative (median survival 42 vs. 29 months, $p=0.37$; $\mathrm{HR}=1.64,95 \% \mathrm{CI}: 1.01-2.67$ ), and triple-negative breast cancer (TNBC) compared to other subtypes (median survival 16 vs. 38 months, $p=$ 0.038; $\mathrm{HR}=1.66,95 \% \mathrm{CI}: 1.02-2.72$ ), (Fig. 1).

\section{Discussion}

The proportion of YBCs in our study (11.4\%) was twice as high as the frequency in the US and Europe (5-7\%) $[13,14]$. This finding supports earlier data suggesting lower age at diagnosis in Indonesia than those countries [2]. The reason for these differences is not clear. Biologically, YBCs in our study showed aggressive phenotypes with relatively high proportion of large tumor size, lymph node involvement, advanced and metastatic diseases, high histology grade, angiolymphatic invasion, Her-2 positivity, TNBC subtype, as well as frequent progression and relapse during follow-up (Table 2) in accordance with previous studies [6, 15-17]. In a large prospective study $(N=2956)$ investigating factors related to poor prognosis in YBCs, 50\% subjects were lymph node positive, $30 \%$ were hormone receptor negative, $20 \%$ patients were TNBC subtype, and $60 \%$ had histologically poor differentiation [18].

Breast-conserving surgery (BCS) and sentinel node biopsy followed by breast radiation are recommended for YBCs [19]. Only 5\% of our patient cohorts were assigned for BCS for the reason of high proportion of advanced stages and the long waiting list for radiotherapy. In addition, cosmetic consideration, immediate breast reconstruction surgery, and impact on body image and sexuality should be offered to YBCs [19]. In advanced cancer, however, radical surgery is preferred to achieve locoregional control and reduce relapse.

Around 88 and $70 \%$ of YBCs in this study completed chemotherapy and radiotherapy, respectively. Hormonal therapy was delivered in $84 \%$ of patients with hormone receptor positive. No specific chemotherapeutic regiment is recommended for YBCs and regiments are usually assigned according to IHC-subtyping [19]. Recent trials using multigene assays suggest that ER-positive and premenopausal early-stage breast cancer (node negative) with low recurrence score might not require chemotherapy [20,21]. The trials included YBCs (3.5 and $2 \%$ in TAILORx and MINDACT, respectively) [20, 21] although application of multigene tests is still far from a practice routine in LMICs including Indonesia. However, the most important challenge in Indonesia is to diagnose young women 
A

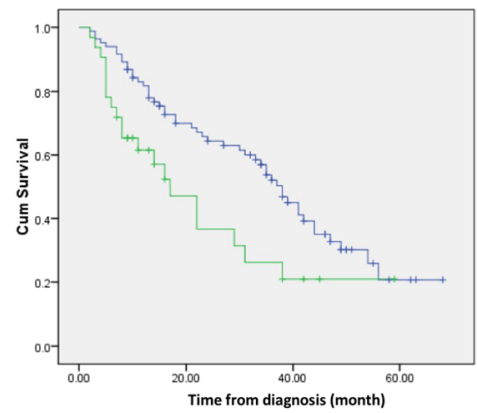

C

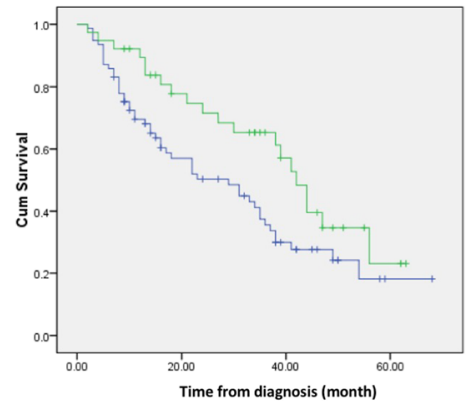

B
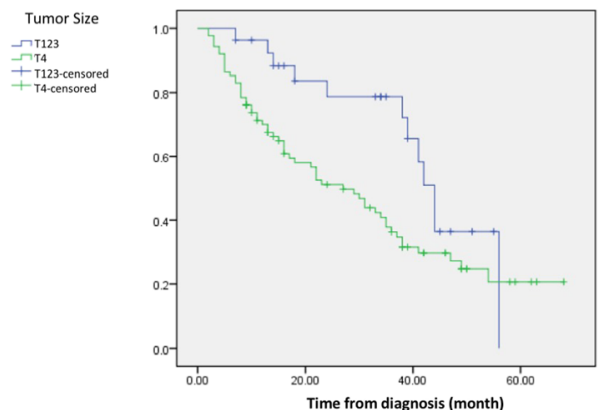

D

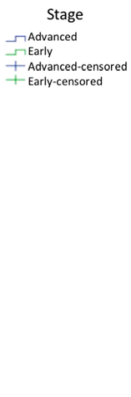

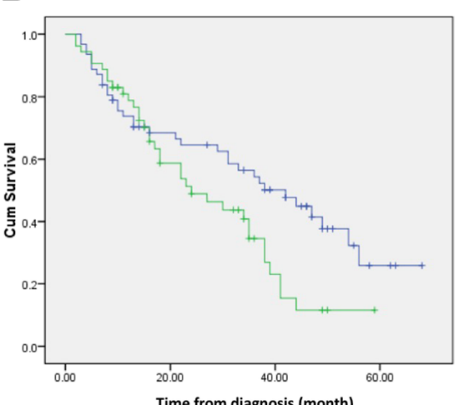

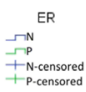

$\mathbf{E}$

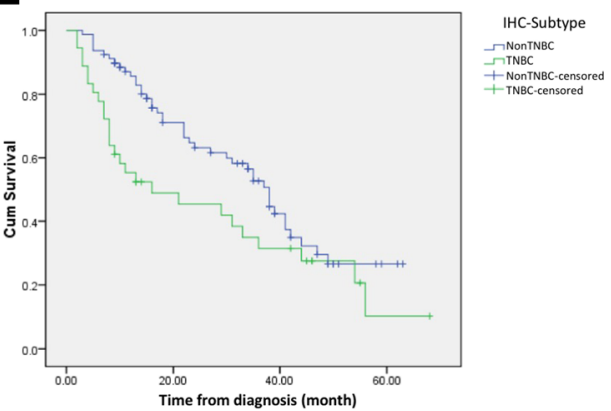

Fig. 1 Progression free survival correlated to some parameters in YBCs. PFS of YBCs was significantly shorter (a) in YBCs with skin or chest wall infiltration (T4) compared to those without skin/chest wall infiltration (T1-T3) (median survival 16 vs. 35 months, $p=0.011 ; \mathrm{HR}=1.89$, 95\%Cl: 1.123.21); $\mathbf{b}$ in YBCs with positive lymph node infiltration compared to node negative (median survival 24 vs 42 months, $p=0.041 ; H R=1.95,95 \% \mathrm{Cl}$ : 1.05-3.64); $\mathbf{c}$ in YBC with hormonal receptor positive compared to negative (median survival 42 vs. 29 months, $p=0.37$; HR=1.64, 95\%Cl: 1.012.67), and (d) in triple-negative YBCs compared to other subtypes (median survival 16 vs 38 months, $p=0.038 ; \mathrm{HR}=1.66,95 \% \mathrm{Cl}: 1.02-2.72$ )

in the early stages (T1-T2, node negative). Hormonal therapy is recommended in premenopausal women with hormonal-receptor positive $(\geq 1 \%$ cell positive for ER or PR) although patients with $\geq 10 \%$ cell positive are the most responsive to adjuvant hormonal therapy [22]. Radiotherapy with the addition of regional nodal irradiation (RNI) is correlated with better PFS and stronger effect is found in patients with ER-negative which is more common in YBCs [23]. Despite following general recommendations for treatment of young breast cancer, the frequency of disease progression in our cohort is relatively high (24\%). We also found a high proportion of patients who did not receive chemotherapy and radiotherapy. Factors associated with barriers to treatment (surgery, chemotherapy, and radiation) as well as to therapy adherence in YBCs require further study [24]. In addition to the aggressive biology of YBCs, advanced stages at diagnosis contribute to the frequent relapse and unfavorable PFS (Fig. 1 section A). The majority of YBC patients were living in a rural residence with low education levels which might contribute to the late presentation for medical treatment although our study indicated that those factors were not associated with barriers to receive chemotherapy and radiotherapy. Our previous study showed relatively low breast cancer awareness among Indonesian women particularly those with low social 
economic status and low education levels [8]. Misunderstanding about breast cancer and the benefits of early detection might also hamper health-seeking attitudes.

More than $13 \%$ of patients in our study developed bilateral breast cancer and $7.6 \%$ with positive family history implicating the increased genetic risk in YBCs. However, genetic service, in general, is not available in most LMICs including in Indonesia. One previous study suggested that genetic counseling and understanding of personal genetic risk is associated with distress reduction and improvement of patient's wellbeing [25]. YBC patients also need particular attention regarding psychosocial factors and fertility concern [26, 27]which were not yet adequately addressed in our clinics. Identification of unmet psychosocial needs and appropriate interventions are important to promote psychological acceptance to the disease [26, 28, 29]. In addition, advanced cancers also are associated with increasing cancer-related disability and poor functioning which require rehabilitation to improve quality of life. However, we previously reported that cancer rehabilitation is also either not available or sub-optimally delivered in developing countries [30, 31].

This present study appears as the first in a series focusing on the clinicopathological profile, treatment choice, and prognosis in Indonesian YBCs. A limitation in this study was that we only included breast cancer patients who were treated in the Department of Surgery, thereby our data may have not included terminally ill patients for whom any surgery was not indicated. This may have resulted in an underestimation of disease progression in our study. A population-based study is, therefore, necessary to replicate our findings in a wider population. Additionally, the hospital is a tertiary referral hospital that treats more complex and advanced stage cancers because a vertical referral system has been implemented in the national health insurance [32]. More collaborative studies are required since the nation-wide cancer registry in Indonesia is not yet comprehensively available [33] to record all YBCs, demographic data, pathological profiles, and survival rates.

\section{Conclusions}

There was a higher proportion of YBC compared to the rates in developed countries. Identification of both biological and clinical factors associated with effective treatment and prognosis are essential to improve YBC patients' outcome and well-being. Several challenges in managing YBCs in Indonesia are a late presentation at diagnosis, frequent relapse and poor survivals, and aggressive type of cancer, with high rates of non-adherence to adjuvant chemotherapy and radiotherapy which may be addressed through further research.

\section{Endnotes}

${ }^{1}$ mSBR is modified Scarff Bloom Richardson grading system (also known as Nottingham system) in which tumor is semi-quantitatively assessed according to percentage of tubule formation (score 1-3 for $75 \%, 10-75$, and $<10 \%$ ), nuclear polymorphism (score $1-3$ for uniform small cells, moderate variation, marked variation), and mitotic counts per 10-40 fields (score $1-3$ for $0-5$, $6-10$, and $>11$ ). The sum of the score determines the grade: Grade 1 [3-5], Grade 2 [6, 7], Grade 3 [8, 9]. (REF \#10)

\section{Abbreviations}

AJCC: American Joint Committee on Cancer; BCS: Breast Conserving Surgery; BMC: BioMed Central; Cl: Confidence Interval; ER: Estrogen Receptor; FISH: Fluorescence in Situ Hybridization; HER2: Human epidermal growth factor receptor 2; HR: Hazard Ratio; IBM: International Business Machine Corporation; IHC: Immunohistochemistry; LMIC: Low-Middle Income

Countries; MINDACT: Microarray in Node-Negative and 1 to 3 Positive Lymph Node Disease May Avoid Chemotherapy; mSBR: Modified System Bloom and Richardson; PFS: Progression Free Survival; PR: Progesterone Receptor; RNI: Regional Nodal Irradiation; SPSS: Statistical Package for the Social Sciences; TAlLORx: Trial Assigning Individualized Options for Treatment; TNBC: Triple-Negative Breast Cancer; TNM: Tumor Node Metastasis; WHO: World Health Organization; YBC: Young Breast Cancer

\section{Acknowledgments}

We specifically thank the patients and their family who participated in this study. We express our gratitude to the staff of Klinik Bahasa for proofreading the manuscript draft.

\section{Funding}

SLA received PTUPT (1818/UNI/DITLIT/DIT-LIT/LT/2018) and PPUPT (1987/ 2018) grants from the Ministry of Research, Technology, and Higher Education - Republic of Indonesia. TA received NUS-UGM Tahir Foundation seed grant. The funders had no role in the study design, data collection, analysis, and interpretation as well as in the manuscript preparation.

\section{Availability of data and materials \\ The datasets analyzed of the present study could be obtained from the corresponding author upon reasonable request.}

\section{Authors' contributions}

SLA and TA conceived and designed the study. SLA, CAR, RH, EKD, DSH, WSA, LC collected the data and performed analysis and interpretation. SLA wrote the first draft with critical feedback from WW, TA, DD, and WAH. All authors read, reviewed and edited the draft and approved the final version of the manuscript.

\section{Ethics approval and consent to participate}

The study was approved by the Medical and Health Research Ethics Committee of the Faculty of Medicine Public Health and Nursing, Universitas Gadjah Mada Indonesia (601/EC/2014 and 1143/EC/2017). All participants gave written informed consent prior to participating in this study.

Consent for publication

Not applicable.

Competing interests

All authors declare that they have no competing interests. 


\section{Publisher's Note}

Springer Nature remains neutral with regard to jurisdictional claims in published maps and institutional affiliations.

\section{Author details}

'Division of Surgical Oncology-Department of Surgery, Faculty of Medicine, Public Health and Nursing, Universitas Gadjah Mada (Dr. Sardjito Hospital), Jalan Kesehatan No 1, Yogyakarta 55281, Indonesia. ${ }^{2}$ PILAR Research and Education, 20 Station Road, Cambridge CB1 2JD, UK. ${ }^{3}$ Department of Anatomical Pathology - Faculty of Medicine, Public Health and Nursing, Universitas Gadjah Mada (Dr. Sardjito Hospital), Yogyakarta 55281, Indonesia. ${ }^{4}$ Department of Radiology - Faculty of Medicine, Public Health and Nursing, Universitas Gadjah Mada (Dr. Sardjito Hospital), Yogyakarta 55281, Indonesia. ${ }^{5}$ Division of Surgical Oncology-Department of Surgery, Faculty of Medicine Universitas Andalas (Dr. M Jamil Hospital), Padang 25127, Indonesia. ${ }^{6}$ MRC Unit for Lifelong Health and Ageing, University College London, Place London, Bedford 33, London, UK

Received: 18 July 2018 Accepted: 23 January 2019

Published online: 06 February 2019

\section{References}

1. Bray F, Ferlay J, Soerjomataram I, Siegel RL, Torre LA, Jemal A. Global Cancer statistics 2018: GLOBOCAN estimates of incidence and mortality worldwide for 36 cancers in 185 countries. CA Cancer J Clin. 2018;68(6):394-424. https://doi.org/10.3322/caac.21492.

2. World Health Organization. Cancer country profile 2014. Cancer Country Profile: Indonesia 2014. https://www.who.int/cancer/country-profiles/idn_en. pdf?ua=1. Accessed 29 Jan 2019

3. Smittenaar CR, Petersen KA, Stewart K, Moitt N. Cancer incidence and mortality projections in the UK until 2035. Br J Cancer. 2016;115(9):1147-55. https://doi.org/10.1038/bjc.2016.304

4. Siegel R. Cancer statistics, 2017. CA Cancer J Clin. 2017;67(1):7-30. https:// doi.org/10.3322/caac.21387

5. Goldhirsch A, Winer EP, Coates AS, et al. Personalizing the treatment of women with early breast cancer: highlights of the St Gallen international expert consensus on the primary therapy of early breast Cancer 2013. Ann Oncol. 2013;24(9):2206-23. https://doi.org/10.1093/annonc/mdt303.

6. Bakkach J, Mansouri M, Derkaoui T, et al. Clinicopathologic and prognostic features of breast cancer in young women: a series from north of Morocco. BMC Womens Health. 2017:17(1). https://doi.org/10.1186/s12905-017-0456-1.

7. Azim HA, Partridge AH, Azim HAJ. Biology of breast cancer in young women. Breast Cancer Res. 2014;16(3):427. https://doi.org/10.1186/s13058014-0427-5.

8. Anwar SL, Tampubolon G, Van Hemelrijck M, Hutajulu SH, Watkins J, Wulaningsih W. Determinants of cancer screening awareness and participation among Indonesian women. BMC Cancer. 2018;18(1). https:// doi.org/10.1186/s12885-018-4125-z.

9. Edge SB, Compton C. The American Joint Committee on Cancer: The 7th edition of the AJCC cancer staging manual and the future of TNM. Ann Surg Oncol. 2010;17(6):1471-4. https://doi.org/10.1245/s10434-010-0985-4.

10. Genestie C, Zafrani B, Asselain B, et al. Comparison of the prognostic value of Scarff-bloom-Richardson and Nottingham histological grades in a series of 825 cases of breast cancer: major importance of the mitotic count as a component of both grading systems. Anticancer Res. 1998;18(1 B):571-6.

11. Sinn HP, Kreipe H. A brief overview of the $W H O$ classification of breast tumors, 4th edition, focusing on issues and updates from the 3rd edition. Breast Care. 2013;8(2):149-54. https://doi.org/10.1159/000350774.

12. Ainsworth BE, Haskell WL, Whitt MCMC, et al. Compendium of physical activities: an update of activity codes and MET intensities. Med Sci Sport Exerc. 2000;32(Supplement):S498-516. https://doi.org/10.1097/00005768200009001-00009.

13. Gnerlich JL, Deshpande AD, Jeffe DB, Sweet A, White N, Margenthaler JA. Elevated breast cancer mortality in women younger than age 40 years compared with older women is attributed to poorer survival in early-stage disease. J Am Coll Surg. 2009;208(3):341-7. https://doi.org/10.1016/j. jamcollsurg.2008.12.001.

14. Renard F, Van Eycken L, Arbyn M. High burden of breast cancer in Belgium: recent trends in incidence (1999-2006) and historical trends in mortality (1954-2006). Arch Public Heal. 2011;69(1):1-11. https://doi.org/10.1186/07787367-69-2.
15. Collins LC, Marotti JD, Gelber S, et al. Pathologic features and molecular phenotype by patient age in a large cohort of young women with breast cancer. Breast Cancer Res Treat. 2012;131(3):1061-6. https://doi.org/10.1007/ s10549-011-1872-9.

16. Ahn SH, Son BH, Kim SW, et al. Poor outcome of hormone receptor-positive breast cancer at very young age is due to tamoxifen resistance: nationwide survival data in Korea--a report from the Korean breast Cancer society. J Clin Oncol. 2007;25(17):2360-8. https://doi.org/10.1200/JCO.2006.10.3754.

17. Zabicki K, Colbert JA, Dominguez FJ, et al. Breast cancer diagnosis in women $\leq 40$ versus 50 to 60 years: increasing size and stage disparity compared with older women over time. Ann Surg Oncol. 2006;13(8):1072-7. https://doi.org/10.1245/ASO.2006.03.055

18. Copson E, Eccles B, Maishman T, et al. Prospective observational study of breast cancer treatment outcomes for UK women aged 18 - 40 years at diagnosis: the POSH study. J Natl Cancer Inst. 2013;105(13). https://doi.org/ 10.1093/jnci/djt134.

19. Paluch-Shimon S, Pagani O, Partridge AH, et al. ESO-ESMO 3rd international consensus guidelines for breast Cancer in young women (BCY3). Breast. 2017;35:203-17. https://doi.org/10.1016/j.breast.2017.07.017.

20. Geyer CE, Dees EC, Goetz MP, et al. Adjuvant chemotherapy guided by a 21-gene expression assay in breast cancer. N Engl J Med. 2018:1-11. https:// doi.org/10.1056/NEJMoa1804710.

21. Cardoso F, van't Veer LJ, Bogaerts J, et al. 70-gene signature as an aid to treatment decisions in early-stage breast cancer. N Engl J Med. 2016;375(8): 717-29. https://doi.org/10.1056/NEJMoa1602253.

22. Fujii T, Kogawa $T$, Dong $W$, et al. Revisiting the definition of estrogen receptor positivity in HER2-negative primary breast cancer. Ann Oncol. 2017; 28(10):2420-8. https://doi.org/10.1093/annonc/mdx397.

23. Whelan TJ, Olivotto IA, Parulekar WR, et al. Regional nodal irradiation in early-stage breast cancer. N Engl J Med. 2015;373(4):307-16. https://doi.org/ 10.1056/NEJMoa1415340.

24. Lee JY, Min YH. Relationships between determinants of adjuvant endocrine therapy adherence in breast cancer. BMC Womens Health. 2018 Mar 19. 18(1):48. https://doi.org/10.1186/s12905-018-0522-3.

25. Engelhardt EG, Garvelink MM, de Haes JHCJM, et al. Predicting and communicating the risk of recurrence and death in women with early-stage breast cancer: a systematic review of risk prediction models. J Clin Oncol. 2014;32(3):238-50. https://doi.org/10.1200/JCO.2013.50.3417.

26. Ruddy KJ, Greaney ML, Sprunck-Harrild K, Meyer ME, Emmons KM, Partridge $\mathrm{AH}$. Young women with breast cancer: a focus group study of unmet needs. J Adolesc Young Adult Oncol. 2013;2(4):153-60. https://doi.org/10. 1089/jayao.2013.0014.

27. Taha H, Al-Qutob R, Nyström L, Wahlström R, Berggren V. "Voices of fear and safety" Women's ambivalence towards breast cancer and breast health: a qualitative study from Jordan. BMC Womens Health. 2012;12. https://doi. org/10.1186/1472-6874-12-21.

28. Campbell-Enns H, Woodgate R. The psychosocial experiences of women with breast cancer across the lifespan: a systematic review protocol. JBI database Syst Rev Implement reports. 2015;13(1):112-21. https://doi.org/10. 11124/jbisrir-2015-1795.

29. Li L, Yang Y, He J, et al. Emotional suppression and depressive symptoms in women newly diagnosed with early breast cancer. BMC Womens Health. 2015;15(1). https://doi.org/10.1186/s12905-015-0254-6.

30. Anwar SL, Adistyawan G, Wulaningsih W, Erlangga Z, et al. Rehabilitation for cancer survivors: closing the gap in low- and middle income countries. Eur J Phys Rehabil Med. 2018. https://doi.org/10.23736/S1973-9087.18.04843-8.

31. Anwar SL, Adistyawan G, Wulaningsih W, Gutenbrunner C, Nugraha B. Rehabilitation for cancer survivors: how we can reduce the healthcare service inequality in low- and middle income countries. Am J Phys Med Rehabil. 2018;97(10):764-71. https://doi.org/10.1097/PHM. 0000000000000982

32. BPJS (Badan Penyelenggara Jaminan Sosial) Kesehatan. Ringkasan eksekutif laporan pengelolaan program dan laporan keuangan jaminan sosial kesehatan. 2016. https://bpjs-kesehatan.go.id/bpjs/dmdocuments/ b39df9ae7a30a5c7d4bd0f54d763b447.pdf. Accessed 29 Jan 2019.

33. Wahidin M, Noviani R, Hermawan S, Andriani V, Ardian A, Djarir H. Population-based cancer registration in Indonesia. Asian Pacific J Cancer Prev. 2012;13(4):1709-10. https://doi.org/10.7314/APJCP.2012.13.4.1709. 